\title{
Cognitive States in Educational Activity of Students: Structural-Functional Aspect
}

\author{
Alexander Oktyabrinovich Prokhorov ${ }^{1}$, Albert Valentinovich Chernov $^{1} \&$ Mark Gennadjevich Yusupov $^{1}$ \\ ${ }^{1}$ Kazan Federal University, Russian Federation \\ Correspondence: Alexander Oktyabrinovich Prokhorov, Kazan Federal University, Kremlevskaja Street, 18, \\ 420008, Kazan, Russian Federation.
}

Received: July 13, 2014 Accepted: October 8, 2014 Online Published: December 2, 2014

doi:10.5539/ass.v11n1p213 URL: http://dx.doi.org/10.5539/ass.v11n1p213

\begin{abstract}
Modern educational systems are aimed at not only knowledge acquisition, but also at intellectual development of young people, including the ability of self-regulation of cognitive activity. That is why the knowledge of students about cognitive states, strengthening the availability of subjective experience, promoting maximum productiveness of cognitive processes gain great significance. The ability to control these states influences directly on the development of cognitive abilities of students and the success of their study in whole. The purpose of this article is to study the structure and functions of typical cognitive states, emerging in the course of students' educational activity. By means of the procedure of factor analysis, there were revealed four independent factors, underlying the structure of cognitive states. It was shown that the factor of metacognitive regulation of cognitive activity acts as a leading one in the structure of states. In comply with the peculiarities of structural organization, there were distinguished the regulating, activating and directing functions of cognitive states.
\end{abstract}

Keywords: cognitive states, educational activity, metacognitive processes, structure, functions

\section{Introduction}

In the process of mental activity, there appear specific feelings, reflecting qualitative peculiarities of its course, as well as the measure of success of intellectual forces. These feelings present personal cognitive states. Historically, four directions of their study can be distinguished.

The first direction is connected with the analysis of scarcely perceptible affective "traces" in the structure of thinking process. W. James (1884) was one of the first, who pointed at distinctive features of "intellectual feelings", which significantly differ from simple emotions, connected with corporal feelings. First of all, it is a sharpen ability to judgments, alongside with damped emotional sensitivity.

E. Klapared (1928), supported by the ideas of W. James, included all thinking elements, which do not participate in reflection of subject content, to intellectual emotions (the majority of relations, expressed by conjunctions but, if and others). Following the functionalism, the author related any intellectual feeling to adaptive reactions of organism.

It shall be noted, that under this direction the intellectual emotions act as "cognitive acts" and in this sense cannot be considered as psychic states (as the aspect of feelings is not covered). At the same time intellectual feelings are connected with perception of thinking processes. For this reason it is believed, that when studying intellectual emotions, it is necessary to take into consideration the reflexive processes. In support of this, it is possible to refer to theoretical statements of metacognitivism, according to which there are special metacognitive processes, performing the regulation function of cognition (Fleming \& Frith, 2014). Reflection is included to metacognitive processes, and it forms an inseparable whole with the basic processes of information processing (Lysaker et al., 2011; Thomas, 2012).

The following logical step is the inclusion of self-control to the structure of cognitive states, as the self-control is the subject's rational reflection and evaluation of his own actions based on personal significant motives and orientations (Nikiforov, 1989).

Under the second direction, the cognitive states are considered as psychic states, which are characterized by domination of cognitive processes in their integral structure (Prokhorov, 1998). Here, not only states, connected 
with thinking process (reflection et al.) are included to the states, but also the ones, appearing in consequence of activity of any other cognitive process, for instance, dreaminess. In the context of this approach, the cognitive states act as "a background" of cognitive activity, at that, the factors of physiological sub-systems, behavior, feelings and cognitive processes were analyzed.

One of the problems when including one or another state to the group of cognitive ones is in revelation of the dominant component. For instance, what state is the interest: cognitive, emotional or volitional?

The third direction is connected with the studies of emotional regulation of thinking processes. In keeping with this approach, it was experimentally proved that emotions are significantly included to the process of task solution, determining the decision-making process. Moreover, the right decision of difficult rational tasks is impossible without participation of emotions (Tukhomirov, 2002).

One of the problems in the study of intellectual emotions lies in the fact, that the majority of them are not specific only for thinking activity. For instance, the astonishment can be the emotional reaction to perception of any unexpected object. Consequently, theoretical separation of the group of intellectual emotions, performing specific functions, is ill founded.

The fourth direction considers the cognitive states as affective-cognitive complexes (Izard, 1991). A specific peculiarity of intellectual emotions is the absence of valence coloring ("pleasant - unpleasant"). On this basis some researchers refuse to refer the states of astonishment, doubt, interest to the category of emotions (Ortony et al., 1988). However, these states are not emotions in traditional understanding - these are the cognitive-affective complexes. For instance, the interest is a positive state, which is experienced as a feeling of capture, curiosity. Its main function is to organize and motivate cognitive activity.

In conclusion of theoretical review, let us note that the considered directions of studies provide an important information about structural peculiarities of cognitive states (metacognitive regulation), directions of their study (a system approach), a method of actualization (activity arrangement) and a principle of interpretation of the obtained results (regulation of thinking processes). Based on these statements, we carried out the empiric investigation of structure and functions of cognitive states in students' educational activity.

\section{Procedure}

The empiric investigations were carried out in conditions of real educational activity of students. In the beginning of the lesson, the cognitive psychic states of the test people became actual. The solution of this task was facilitated by the fact, that these states are the most typical for the students' educational activity, and they appear naturally in the course of training process.

The procedure of execution of psychological tests was presented as a cognitive task, at that, much attention was paid to the procedures and results of their execution from the viewpoint of communication, self-actualization and professional advancement. Hence, for the students the situation of investigation acquired a definite personal meaning, connected with the dominant interests of adolescent age. According to a longstanding teaching practice, the abovementioned methodic device allows initiating the cognitive activity of students and its accompanying states.

To measure the cognitive states, we developed a procedure, providing an opportunity to carry out self-evaluation of main components of the state as per 10-point scale: psychic processes, physiological reactions, feelings and behavior (40 factors in total) (Prokhorov, 1998). There were also measured the cognitive styles (Gardner et al., 1959), the factors of training styles (Litzinger et al., 2007), different aspects of reflection (Grant, 2001), metacognitive involvement into activity (Schraw, 1994), self-control (Nikiforov, 1989), personal traits of test people (Cattell \& Mead, 2008). The productivity of cognitive processes was evaluated as per the results of specially selected tests (Anastasi \& Urbina, 1997): exclusion of notions (to delete from five words the one, not corresponding in meaning), number series (to continue the number series, revealing its pattern), spatial generalization (imaginable turn of the three-D block and its juxtaposition with another blocks), thinking logics (mathematical tasks to compare the abstract values), complex analogies (verbal tasks to build the analogies as per the provided samples), concentration and switching of attention, work memory (execution of digital arithmetic in intellectual plane), sense bearing (memorizing of words) and mechanical (memorizing of numbers) memory.

The second- and third-year students of the Kazan Federal University with the average age of 19.6 years made up the survey sample ( 77 people in total). The results of investigation were proceeded by means of statistics package SPSS 19.0. 


\section{The Results}

The analysis of self-reports of test people showed the following frequency of occurrence of the cognitive states: interest (58\%), reflection (32\%), curiosity (4\%), bewilderment (3\%), and concentration (3\%).

Let us consider the structure of cognitive states, obtained as per the results of factor analysis (the principle component method, promax rotation). From the viewpoint of simplicity, the four-factor decision had the best opportunities for interpretation (Preacher et al., 2013). The obtained factors explain $71 \%$ of dispersion of the initial set of characteristics.

The first factor included the following variables (the values of factor loadings are shown in brackets): reasoning of behavior (.921), reflection of future (.897), controllability of behavior (.818), consistency of behavior (.803), general level of reflexivity (.779), reflection of the present (.736), competence (.725), G factor ("normalization of behavior") (.723), cognitive style "wide range of equivalence" (.707), self-control of activity (.704), sequence of behavior (.685), will (.638), logical thinking (.610), metacognitive involvement into the activity (.603), confidence of behavior (.586), main memory (.578), self-control of communication (.558), optimism of feelings (.556), switching of attention (.537). This factor explains $25 \%$ of dispersion of initial variables.

The second factor (19\% of dispersion of factors) included the following variables: gaiety of feelings (.916), liveliness of feelings (.908), teasing feelings (.883), loftiness of feelings (.867), activity of feelings (.813), activity of behavior (.806), emotions of joy and delight (.804), tension of behavior(.772), vivacity of feelings (.770), lightness of feelings (.698), openness of behavior (.695), physical activity (.691), blushing of face, neck and arms (.548).

The third factor (15\% of dispersion of factors) is formed by the following variables: the reflexive style of training (.893), $\mathrm{Q}_{2}$ factor ("independence") (.881), A factor ("sociability") (-.850), F factor ("expressivity") (-.829), communicative reflection (.739), $\mathrm{Q}_{1}$ factor ("radicalism") (.730), reflection of the past (.671), L factor ("suspiciousness") (.642), exclusion of notions (.576), intuitive style of training (.571), concentration of attention (.442), complex analogies (.385), semantic memory (.379), mechanical memory (.334).

The last fourth factor (explains $12 \%$ of variations of initial factors) includes the following variables: I factor ("sensibility") (.789), $\mathrm{H}$ factor ("courage") (.739), breath activity (.718), heart-vascular system activity (.699), analytical style of training (.633), feelings on the part of the digestive tract (.610), number series (.604), spatial generalizations (.599).

Table 1. A matrix of intercorrelations of factors, underlying the structure of cognitive states

\begin{tabular}{ccccc}
\hline Factors & 1 & 2 & 3 & 4 \\
\hline 1 & 1.00 & .079 & .080 & .010 \\
2 & .079 & 1.00 & -.061 & .071 \\
3 & .080 & -.061 & 1.00 & -.022 \\
4 & .010 & .071 & -.022 & 1.00 \\
\hline
\end{tabular}

In the end of review of results, let us pay attention to general peculiarity of structure of cognitive states - small values of intercorrelations between the distinguished factors (see Table 1). Thus, the structural-functional organization of cognitive states is based on four relatively independent factors, which can be considered as their basis.

\section{Discussion}

Before discussing the results, we would like to emphasize that the structure of cognitive states was studied on the example of the interest - the most typical state in the learning activities of students. Therefore, the identified factors reflect the essence of this particular condition. However, it can be assumed that the cognitive status of students in the learning process has some common characteristics, the study of which is the subject of the future research.

Consider the structure of the first factor. The groups of variables are clearly distinguished in its structure; they refer to controllability of behavior, metacognitive regulation of cognitive processes and self-regulation of activity. It is interesting to note that $\mathrm{G}$ factor in its essence in also a regulation factor of behavior in comply with the definite norms and rules. The subjects with high estimates as per this scale are characterized by persistence in achievement of goals, responsibility and businesslike character. 
The inclusion of cognitive style "the wide range of equivalence" into this factor looks like a curious fact. The predominance of wide categories ("syntheticity") provides an opportunity to operate with large volume of comparable data, manifested in the tendency to single out hidden regularities in the test object (Blazhenkova \& Kozhevnikov, 2012). The obtained results show that this stylistic parameter of cognitive activity is considerably connected with the metacognitive processes.

Thus, taking into consideration the fact, that in context of education, the behavior acquires the characteristics of task-oriented activity, the first factor can be denoted as "the metacognitive regulation of activity".

The function of this factor is to direct the subject to the in-depth knowledge of the teaching material and build a logically consistent communication between existing and new knowledge. Thus the state of interest is not only as a motivational and emotional state, but it is primarily as a metacognitive state associated with generation and understanding of new experiences. The legitimacy of such an approach to the state of interest is confirmed by studies of American psychologist P. Silvia (2008). In particular, the author and his colleagues released a function of interest as filling (replenishment), contributed to the deepening of knowledge (Thoman et al., 2011).

The content of the second factor reflects the statics of emotions and activity of behavior. Besides, the structure of this factor includes the energetic factors, connected with activity of physiological subsystems. Taking into consideration the predominance of feelings in this group of variables and their high factor loadings, this factor can be named as a factor of "emotional mobilization of activity".

This factor reflects the generally accepted ideas about the state of interest, according to which it includes cognitive and affective components (Hidi et al., 2004).

Let us note one more peculiarity - the presence of factor of exclusively positive pole of emotions in the structure. Thus, the cognitive states manifest themselves as positive psychic phenomena. This has important implications for education as positive conditions significantly improve the efficiency of learning (Khar Thoe Ng at al., 2012; Rowe at al., 2013). Generation of cognitive states during the training should be one of the tasks of the teacher (Chiang \& Liu, 2014).

In the structure of the third factor the variables of personal traits and styles of training possess the most weighty factor loadings. The last ones reflect the individual peculiarities of information processing (Boström \& Hallin, 2013).

Thus, the preference of reflexive style is expressed thorough reflection and imaginable categorization of information prior to its usage. The predominance of intuition testifies tendency to percept the abstract regularities, the abilities to perform efficiently the cognitive activity in situations of information deficit.

It is easy to note that the specific features of training styles and personal traits, included to the marked factor, are, in their essence, typical of the introverted subjects. Taking into consideration, that the factor presents the reflexive regulation of information processing in the situations, connected with training, it can be denoted as "the intrapsychic activity".

As for the last factor, let us note that I and $\mathrm{H}$ factors are referred to the group of emotional characteristics of the personality. The variable "analytical style of training" characterizes the students from the viewpoint of predominance of analytical thinking processes over the synthetic ones. Summing up the constituents of the factor based on the meaning, let us identify it as "the emotional-personal regulation of thinking".

The essence of this factor is the experience of the individual characteristics of interest. For example, the cognitive style of personality, which determines the interpretation of the learning situation, affects the interpretation of the interest. (Silvia et al., 2009). Since the interest is a situational state, then states based on different interpretations may have a qualitatively different structure. Furthermore, the development and stabilization of the motivational system of students and the corresponding interest is a powerful source of personal regulation of cognition (Hidi \& Renninger, 2006).

Thus, our results do not contradict the prevalent notion of the cognitive states and the state of interest in particular. At the same time, most of the studies on these conditions were performed in laboratory conditions, which impose limitations on the practical application of the results. This study, conducted in the real conditions of learning activities of students, reveals a relatively new aspect of cognitive states associated with the regulation of metacognitive knowledge and the learning process in general.

\section{Conclusions and Summary}

The conducted research has the restrictions. The generalized characteristics of cognitive states are received on the example of condition of interest. Studying of the structure and functions of the other states that are most 
often experienced by students in the learning process is the prospect of further research. Nevertheless, we were able to establish the following facts.

The leading function of cognitive states is the metacognitive regulation of activity, covering social-psychological, pragmatic and cognitive aspects of personality. The other functions of cognitive states involve emotional activation of thinking activity (activation-energy function, connected with the changes of vegetative functions and activation of cortical brain divisions), intentional functions (activation of intrapsychic direction) and the function of emotional-personal regulation, connected with the activity of emotional traits of personality.

The structure of cognitive states significantly integrates the individual traits of personality, including stylistic parameters of training, thus, they act as personal psychic states.

The factors of cognitive processes take the subordinate place in relation to main variable factors, testifying about the influence of metacognitive and personal characteristics on organization of cognitive activity. Such strong regulation of information processing provides an opportunity to speak about the unique value of these states in in the problems of successful training.

\section{Acknowledgements}

The investigation was carried out thanks to the support of Russian Humanitarian Scientific Fund, project No. 13-16-16007.

\section{References}

Anastasi, A., \& Urbina, S. (1997). Psychological Testing (7th ed., p. 721). Prentice Hall, Upper Saddle River, NJ.

Blazhenkova, O., \& Kozhevnikov, M. (2012). Intellectual Styles in Members of Different Professions. In L. -F. Zhang, R. J. Sternberg, \& S. Rayner (Eds.), Handbook of Intellectual Styles: Preferences in Cognition, Learning, and Thinking (pp. 353-372). Springer Publishing Company, LLC, New York.

Boström, L., \& Hallin, K. (2013). Learning Style Differences between Nursing and Teaching Students in Sweden: A Comparative Study. International Journal of Higher Education, 2(1), 22-34.

Cattell, H. E. P., \& Mead, A. D. (2008). The sixteen personality factor questionnaire (16PF). In G. Boyle, G. Matthews, \& D. H. Saklofske (Eds.), The SAGE handbook of personality theory and assessment (Vol. 2, Personality measurement and testing, pp. 135-178). CA Sage, Los Angeles.

Chiang, W. -W., \& Liu, C. -J. (2014). Scale of Academic Emotion in Science Education: Development and Validation. International Journal of Science Education, 36(6), 908-928. http://dx.doi.org/10.1080/09500693. 2013.830233

Claparede, E. (1928). Emotions and Feelings. In M. L. Reymert (Ed.), Feelings and emotions: The Wittenberg symposium (pp. 124-139). Massachusetts, USA: Clark University Press.

Fleming, S. M., \& Frith, C. D. (2014). Metacognitive Neuroscience: An Introduction. In The cognitive neuroscience of metacognition (p. 250). Springer-Verlag, Berlin, Heidelberg. http://dx.doi.org/10.1007/9783-642-45190-4_1

Gardner, R. W., Holzman, P. S., Klein, G. S., Linton, H. P., \& Spence, D. P. (1959). Cognitive control: A study of individual consistencies in cognitive behavior (Psychological Issues, Part 4, pp. 1-186). New York: International Universities Press.

Grant, A. M. (2001). Rethinking Psychological Mindedness: Metacognition, Self-reflection, and Insight. Behavior Change, 18(1), 8-17. http://dx.doi.org/10.1375/bech.18.1.8

Hidi, S., \& Renninger, K. A. (2006). The Four Phase Model of Interest Development. Educational Psychologist, 4l(2), 111-127. http://dx.doi.org/10.1207/s15326985ep4102_4

Hidi, S., Renninger, K. A., \& Krapp, A. (2004). Interest, a motivational variable that combines affective and cognitive functioning. In D. Y. Dai, \& R. J. Sternberg (Eds.), Motivation, emotion, and cognition: Integrative perspectives on intellectual functioning and development (pp. 89-115). Mahwah, NJ: Lawrence Erlbaum Associates, Inc.

Izard, C. E. (1991). The Psychology of Emotions (p. 451). Plenum Press, New York. http://dx.doi.org/10.1007/ 978-1-4899-0615-1

James, W. (1884). What is an Emotion? Mind, 9(34), 188-205. http://dx.doi.org/10.1093/mind/os-IX.34.188

Litzinger, T. A., Sang, H. L., Wise, J. C., \& Felder, R. M. (2007). A Psychometric Study of the Index of Learning Styles. Journal of Engineering Education, 96(4), 309-319. http://dx.doi.org/10.1002/j.2168- 
9830.2007.tb00941.x

Lysaker, P. H., Buck, K. D., Carcione, A., Procacci, M., Salvatore, G., Nicolò, G., \& Dimaggio, G. (2011). Addressing Metacognitive Capacity for Self-Reflection in the Psychotherapy for Schizophrenia: A Conceptual Model of the Key Tasks and Processes. Psychology and Psychotherapy: Theo, Res, Pra, 84, 58-69.

Nikiforov, G. S. (1989). Self-Control of a Person (p. 192). The Leningrad State University, Leningrad.

Ortony, A., Clore, G., \& Collins, A. (1988). The Cognitive Structure of Emotions (p. 207). Cambridge: Cambridge University Press. http://dx.doi.org/10.1017/CBO9780511571299

Preacher, K. J., Zhang, G., Kim, C., \& Mels, G. (2013). Choosing the optimal number of factors in exploratory factor analysis: A model selection perspective. Multivariate Behavioral Research, 48, 28-56. http://dx.doi.org/10.1080/00273171.2012.710386

Prokhorov, A. O. (1998). The Psychology of Non-Equilibrium States (p. 152). The Institute of Psychology of the Russian Academy of Sciences, Moscow.

Rowe, A. D., Fitness, J., \& Wood, L. N. (2013). University student and lecturer perceptions of positive emotions in learning. International Journal of Qualitative Studies in Education, 1, 20.

Schraw, G., \& Dennison, R. S. (1994). Assessing Metacognitive Awareness. Contemporary Educational Psychology, 19, 460-475. http://dx.doi.org/10.1006/ceps.1994.1033

Silvia, P. J. (2008). Interest - the curious emotion. Current Directions in Psychological Science, 17, 57-60. http://dx.doi.org/10.1111/j.1467-8721.2008.00548.x

Silvia, P. J., Robert, A. H., \& Templin, J. L. (2009). Are the sources of interest the same for everyone? Using multilevel mixture models to explore individual differences in appraisal structures. Cognition and Emotion, 23(7), 1389-1406. http://dx.doi.org/10.1080/02699930902850528

Thoe Ng, K., Lay, Y. F., Areepattamannil, S., Treagust, D. F., \& Chandrasegaran, A. L. (2012). Relationship between affect and achievement in science and mathematics in Malaysia and Singapore. Research in Science \& Technological Education, 30(3), 225-237.

Thoman, D. B., Smith, J. L., \& Silvia, P. J. (2011). The resource replenishment function of interest. Social Psychological and Personality Science, 2, 592-599. http://dx.doi.org/10.1177/1948550611402521

Thomas, G. P. (2012). Metacognition in Science Education: Past, present and future considerations. In Second International Handbook of Science Education (pp. 131-144). Springer, Dordrecht. http://dx.doi.org/10.1007/978-1-4020-9041-7_11

Tikhomirov, O. K. (2002). The Psychology of Thinking (p. 288). Moscow: Academy Publisher.

\section{Copyrights}

Copyright for this article is retained by the author(s), with first publication rights granted to the journal.

This is an open-access article distributed under the terms and conditions of the Creative Commons Attribution license (http://creativecommons.org/licenses/by/3.0/). 